\title{
Interactions between essential fatty acid, prostanoid, polyol pathway and nitric oxide mechanisms in the neurovascular deficit of diabetic rats
}

\author{
N.E. Cameron ${ }^{1}$, M. A. Cotter ${ }^{1}$, T. C. Hohman ${ }^{2}$ \\ ${ }^{1}$ Department of Biomedical Sciences, University of Aberdeen, Aberdeen, Scotland \\ ${ }^{2}$ Wyeth-Ayerst Research, Princeton, New Jersey, USA
}

Summary Impaired $\omega-6$ essential fatty acid metabolism and exaggerated polyol pathway flux contribute to the neurovascular abnormalities in streptozotocin-diabetic rats. The potential interactions between these mechanisms were examined by comparing the effects of threshold doses of aldose reductase inhibitors and evening primrose oil, alone and in combination, on neurovascular deficits. In addition, highdose aldose reductase inhibitor and evening primrose oil treatment effects were challenged by co-treatment with the cyclo-oxygenase inhibitor, flurbiprofen, or the nitric oxide synthase inhibitor, $\mathrm{N}^{\mathrm{G}}$-nitro-L-arginine. Eight weeks of diabetes caused an $18.9 \%$ reduction in sciatic motor conduction velocity $(p<0.001)$. This was only modestly ameliorated by a $0.1 \%$ dietary supplement of evening primrose oil or the aldose reductase inhibitors ZD5522 $\left(0.25 \mathrm{mg} \cdot \mathrm{kg}^{-1} \cdot\right.$ day $\left.^{-1}\right)$ and WAY121509 $\left(0.2 \mathrm{mg} \cdot \mathrm{kg}^{-1} \cdot \mathrm{day}^{-1}\right)$ for the final 2 weeks. However, joint treatment with primrose oil and ZD5522 or WAY121509 caused marked 71.5 and $82.4 \%$ corrections, respectively, of the conduc- tion deficit. Sciatic nutritive blood flow was $43.1 \%$ reduced by diabetes $(p<0.001)$ and this was corrected by $67.8 \%$ with joint ZD5522 and primrose oil treatment $(p<0.001)$. High-dose WAY121509 (10 $\left.\mathrm{mg} \cdot \mathrm{kg}^{-1} \cdot \mathrm{day}^{-1}\right)$ and primrose oil $(10 \%$ dietary supplement) prevented sciatic conduction velocity and nutritive blood flow deficits in 1-month diabetic rats $(p<0.001)$. However, these effects were abolished by flurbiprofen $\left(5 \mathrm{mg} \cdot \mathrm{kg}^{-1} \cdot \mathrm{day}^{-1}\right)$ and $\mathrm{N}^{\mathrm{G}}$-nitro-Larginine $\left(10 \mathrm{mg} \cdot \mathrm{kg}^{-1} \cdot \mathrm{day}^{-1}\right)$ co-treatment $(p<$ 0.001 ). Thus, the data provide evidence for synergistic interactions between polyol pathway/nitric oxide and essential fatty acid/cyclo-oxygenase systems in the control of neurovascular function in diabetic rats, from which a potential therapeutic advantage could be derived. [Diabetologia (1996) 39: 172-182]

Key words Neuropathy, nerve conduction, endoneurial blood flow, ischaemia, essential fatty acid, prostacyclin, aldose reductase, nitric oxide, vascular endothelium, diabetic rat.
Impaired nutritive blood flow is the major factor contributing to early peripheral nerve dysfunction in experimental diabetes mellitus $[1,2]$. This is likely to be relevant to complications in patients, as direct and indirect investigations have provided strong evidence for nerve perfusion deficits associated with

Received: 12 June 1995 and in revised form: 22 August 1995

Corresponding author: Dr. N. E. Cameron, Department of Biomedical Sciences, University of Aberdeen, Marischal College, Aberdeen AB9 1AS, Scotland, UK

Abbreviations: ARI, Aldose reductase inhibitor; EPO, evening primrose oil; NCV, nerve conduction velocity; NO, nitric oxide; NOLA, $\mathrm{N}^{\mathrm{G}}$-nitro-L-arginine. diabetic neuropathy [3]. In diabetic rats, neurovascular defects can be prevented or corrected by a number of therapeutic strategies that target the metabolic changes in diabetes or compensate for them by a direct vasodilator action on vasa nervorum [2]. Vascular endothelium appears particularly vulnerable to hyperglycaemia-driven metabolic changes in diabetes. Increased synthesis/action of angiotensin II [4] and endothelin 1 [5] promote vasa nervorum vasoconstriction. This is strongly exacerbated by deficits in prostacyclin synthesis [6] and nitric oxide (NO) release/action [7] which reduce local vasodilation. Prostacyclin changes appear to be caused by defective $\omega-6$ essential fatty acid handling due to a 
diabetes-induced deficit in the conversion of linoleic acid to $\gamma$-linolenic acid by $\Delta-6$ desaturase. This defect may be bypassed by dietary supplementation with a $\gamma$-linolenic acid-rich natural source such as evening primrose oil (EPO), thus restoring vasa nervorum prostacyclin synthesis [8] and preventing endoneurial blood flow and nerve conduction velocity (NCV) deficits [9-11]. The NO deficit is related to polyol pathway activity and increased oxygen free radical production, being prevented by aldose reductase inhibitor (ARI) treatment [7] and free radical scavengers [12], which also correct nerve blood flow and NCV abnormalities [13-15]. In non-diabetic rats, NCV reductions are found for chronic treatment with cyclo-oxygenase and NO synthase inhibitors [16]. That study revealed that joint cyclo-oxygenase/NO synthase blockade had a greater effect on NCV than predicted from simple additivity between their individual actions, suggesting that mutual facilitation normally exists between prostacyclin and NO mechanisms in the control of neurovascular function.

To further investigate such interactions in streptozotocin-diabetic rats, and any potential therapeutic implications, two experiments were performed. The first investigated the effects on nerve blood flow and NCV of treatment with "threshold" (minimally effective) doses of EPO and ARIs, alone and in combination. The second examined the ability of cyclooxygenase or NO synthase inhibitors to block the neurovascular effects of high doses of EPO and an ARI.

\section{Materials and methods}

The experiments were performed in accordance with regulations specified in the United Kingdom "Animal Procedures Act, 1986" and the National Institutes of Health "Principles of Laboratory Animal Care, 1985 revised version".

Experimental groups and diabetes induction. Male SpragueDawley rats (Aberdeen University colony) were used, aged 19 weeks at the start of experiments. The first study assessed the effects of low doses of EPO (Scotia Pharmaceuticals, Guildford, Surrey, UK) and a sulphonylnitromethane ARI, ZD5522 (Zeneca Pharmaceuticals, Macclesfield, Cheshire, UK) on sciatic motor NCV and blood flow in streptozotocin-diabetic rats. Experimental groups comprised non-diabetic controls, 8-week untreated diabetic rats, and diabetic rats left untreated for 6 weeks and then given EPO $(0.1 \%$ dietary supplement) or ARI $\left(0.25 \mathrm{mg} \cdot \mathrm{kg}^{-1} \cdot\right.$ day $^{-1}$ orally $)$ or combined EPO/ARI treatment for 2 weeks. These doses were selected to be minimally effective from a knowledge of dose-response relationships for EPO and ZD5522, and the treatment duration was determined from the time course for correction of NCV deficits by these agents $[14,17]$. Supplementary groups were used to further test the possibility of EPO/ARI interaction using a structurally unrelated cyclic imide ARI, WAY121509 (Wyeth-Ayerst Research, Princeton, N.J., USA), at a dose of $0.2 \mathrm{mg} \cdot \mathrm{kg}^{-1} \cdot$ day ${ }^{-1}$ orally, al- though in this case functional measurement was confined to NCV.

The second study examined the effects on NCV and blood flow in diabetic rats of the cyclo-oxygenase inhibitor, flurbiprofen (Sigma, Poole, Dorset, UK) or the NO synthase inhibitor, $\mathrm{N}^{\mathrm{G}}$-nitro-L-arginine (NOLA) (Sigma). These drugs were given in the drinking water such that rats received a dose of approximately $5 \mathrm{mg} \cdot \mathrm{kg}^{-1} \cdot \mathrm{day}^{-1}$ for flurbiprofen or 10 $\mathrm{mg} \cdot \mathrm{kg}^{-1} \cdot$ day $^{-1}$ for NOLA. Subgroups of these rats were also treated with EPO ( $10 \%$ dietary supplement), or WAY121509 administered in the diet such that rats received approximately $10 \mathrm{mg} \cdot \mathrm{kg}^{-1} \cdot \mathrm{day}^{-1}$. The doses chosen of EPO and WAY121509 were at or near the top of their respective dose-response curves $[17,18]$, while doses of flurbiprofen and NOLA were around or below the middle of their respective dose-response relationships in non-diabetic rats [16]. Treatment began at time of induction of diabetes, for 1 month.

Diabetes was induced by an i.p. injection of streptozotocin freshly made up in sterile $154 \mathrm{mmol} \cdot \mathrm{l}^{-1} \mathrm{NaCl}$ solution (40-45 $\left.\mathrm{mg} \cdot \mathrm{kg}^{-1}\right)$. Diabetes was verified after $24 \mathrm{~h}$ by the presence of hyperglycaemia and glucosuria (Visidex II and Diastix; Ames, Slough, UK) in non-fasted rats. After final experiments, plasma glucose was estimated (GOD-Perid method; Boehringer Mannheim, Mannheim, Germany) on samples taken from the carotid artery cannula.

Nerve conduction velocity and blood flow. Rats were anaesthetized with thiobutabarbital sodium (Zeneca) by intraperitoneal injection ( $\left.50-100 \mathrm{mg} \cdot \mathrm{kg}^{-1}\right)$. The trachea and one carotid artery were cannulated for respiratory aid and systemic blood pressure recording, respectively. The core temperature of the rat was regulated in the range $37-38^{\circ} \mathrm{C}$ using radiant heat and was monitored with a rectal probe. The sciatic nerve was exposed from sciatic notch to knee and nerve temperature was kept at $36-37^{\circ} \mathrm{C}$ using radiant heat and was monitored with a near nerve probe. Motor NCV to tibialis anterior muscle was measured as previously described $[10,19]$.

Endoneurial blood flow was measured in the contralateral limb by microelectrode polarography and hydrogen clearance as previously described $[5,19]$. Rats were given neuromuscular blockade using D-tubocurarine (Sigma, $2 \mathrm{mg} \cdot \mathrm{kg}^{-1}$ via the carotid cannula) and artificially ventilated. The level of anaesthesia was monitored by observing any reaction of blood pressure to manipulation, and supplementary anaesthetic was given as necessary. The sciatic nerve was exposed and the skin around the incision was sutured to a metal ring to form a pool which was filled with liquid paraffin at $37^{\circ} \mathrm{C}$. A glass-insulated platinum microelectrode, polarized at $250 \mathrm{mV}$ with respect to a subcutaneous reference electrode, was inserted into the sciatic nerve endoneurium between the sciatic notch and the nerve trifurcation above the knee. Next, $10 \% \mathrm{H}_{2}$ was added to the inspired gas, the proportions of $\mathrm{O}_{2}$ and $\mathrm{N}_{2}$ being adjusted to 20 and $70 \%$, respectively. When the $\mathrm{H}_{2}$ current recorded by the electrode had stabilized, indicating equilibrium with arterial blood, the $\mathrm{H}_{2}$ supply was shut off and $\mathrm{N}_{2}$ delivery was increased appropriately. The $\mathrm{H}_{2}$ clearance was recorded until a stable baseline was reached, which was defined as no systematic decline in electrode current over $5 \mathrm{~min}$. This procedure was then repeated at another nerve site. After the experiment, clearance curves were digitized and mono- or bi-exponential curves were fitted to the data by computer using non-linear regression analysis (Inplot, Graphpad, San Diego, Calif., USA). The bi-exponential equation used was:

$y=a \exp (-b x)+c \exp (-d x)+e$ 
Table 1. Body weights and plasma glucose concentrations for the groups in study 1

\begin{tabular}{|c|c|c|c|c|}
\hline \multirow[t]{2}{*}{ Group } & \multirow[t]{2}{*}{$n$} & \multicolumn{2}{|c|}{ Weight (g) } & \multirow{2}{*}{$\begin{array}{l}\text { Plasma glucose } \\
\left(\mathrm{mmol} \cdot \mathrm{I}^{-1}\right)\end{array}$} \\
\hline & & $\overline{\text { Initial }}$ & Final & \\
\hline Non-diabetic control & 11 & $487 \pm 8$ & - & $7.5 \pm 0.4$ \\
\hline 8-week diabetic + EPO & 10 & $465 \pm 9$ & $292 \pm 18^{\mathrm{a}}$ & $44.4 \pm 1.2^{2}$ \\
\hline 8-week diabetic + ZD5522 & 10 & $467 \pm 11$ & $313 \pm 13^{a}$ & $39.2 \pm 1.8^{a}$ \\
\hline 8-week diabetic + WAY121509 & 9 & $469 \pm 10$ & $331 \pm 13^{a}$ & $43.8 \pm 0.9^{a}$ \\
\hline
\end{tabular}

Data are group means \pm SEM

${ }^{a} p<0.001$ us non-diabetic control group

Where $y$ is the electrode hydrogen current (arbitrary units), $x$ is time ( $\mathrm{min}$ ), $a$ and $c$ are weighting constants for fast (nonnutritive) and slow (nutritive) clearance components respectively, $b$ is the fast component and $d$ is the slow component $\left(\mathrm{ml} \cdot \mathrm{min}^{-1} \cdot \mathrm{ml}\right.$ nerve $\left.{ }^{-1}\right)$, and $e$ is the baseline hydrogen current (arbitrary units). Assuming a tissue density of 1, nutritive blood flow was calculated as $d \times 100\left(\mathrm{ml} \cdot \mathrm{min}^{-1} \cdot 100 \mathrm{~g}^{-1}\right)$ [20]. Composite flow was calculated as $[(a /(a+c)) b+(c /$ $(a+c)) d] \times 100\left(\mathrm{ml} \cdot \mathrm{min}^{-1} \cdot 100 \mathrm{~g}^{-1}\right)[20,21]$. Vascular conductance was calculated by dividing blood flow by the mean arterial blood pressure over the recording period for that particular clearance curve. The percentage of hydrogen clearance carried by the slow (nutritive) component was calculated as $[\mathrm{cl}$ $(a+c)] \times 100$ [21]. The averages from the two determinations were taken to represent sciatic endoneurial blood flow parameters.

Nerve polyol metabolite and myo-inositol determinations. At the end of experiments, before rats were killed by exsanguination, the sciatic nerve in the leg contralateral to the one used for blood flow measurements was rapidly removed, frozen in liquid $\mathrm{N}_{2}$, and stored at $-80^{\circ} \mathrm{C}$ for subsequent analysis. Whole nerve sorbitol, fructose and myo-inositol concentrations were measured as their aldonitrile, cyclitol and alditol acetate derivatives by gas liquid chromatography using flame ionization detection as previously described [18].

\section{Statistical analysis}

Using a commercial software package (Instat, Graphpad) data were analysed with Bartlett's test for homogeneity of variance, and were then subjected to $\log$ transformation if necessary before one-way analysis of variance (ANOVA). Where overall significance $(p<0.05)$ was attained, individual between-group comparisons were made using the Bonferroni or Student-Newman-Keuls range test to correct for multiple comparisons. While data from all groups were approximately normally distributed, where between-group variance differences were sufficiently great that they could not be normalized by $\log$ transformation (nerve sorbitol data from studies 1 and 2, blood pressure data from study 1 , and body weight data from study 2), the Kruskal-Wallace non-parametric ANOVA was used, followed by Dunn's multiple comparison test.

\section{Results}

Study 1: effects of low dose aldose reductase inhibition and evening primrose oil treatment, alone and in combination, on nerve conduction and perfusion. Body weights and plasma glucose values are shown in Table 1. Eight weeks of diabetes caused an approximately $33.5 \%$ reduction in body weight accompanied by hyperglycaemia. This was unaffected by treatment over the final 2 weeks. Sciatic nerve polyol pathway metabolite levels and the effects of diabetes and ARI treatment are shown in Figure 1. Sciatic nerve sorbitol and fructose levels were significantly increased $(p<0.001) 22-$ and 8-fold, respectively, with 8 weeks of diabetes. Two weeks of ZD5522 treatment reduced nerve sorbitol levels by aproximately $64 \%$, although this did not reach statistical significance, and fructose levels were lowered by $46 \%(p<0.001)$. WAY121509 treatment produced a greater effect on nerve polyol pathway metabolite accumulation, significantly reducing $(p<0.001)$ sorbitol and fructose levels by 93 and $74 \%$, respectively. In neither case did co-treatment with EPO significantly alter the efficacy of the ARIs in blocking nerve polyol pathway metabolite accumulation. Nerve samples from the EPO treated diabetic group were not analysed for polyol content. There was a $28.1 \pm 4.8 \%$ reduction $(p<0.001)$ in sciatic myo-inositol concentration with diabetes. This was not reversed by ZD5522 treatment, the value remaining below the non-diabetic level without $(p<0.001)$ or with EPO $(p<0.01)$ co-treatment. For WAY121 509 treatment alone, myo-inositol levels tended to be increased, although this was not statistically significant. However, for the joint WAY121509-EPO treatment group, myo-inositol levels were significantly increased $(p<0.01)$ above that observed in untreated diabetes.

Sciatic motor NCV (Fig. 2) was $18.9 \pm 0.9 \%$ reduced $(p<0.001)$ by diabetes. Nerve function was slightly improved with treatment, the amelioration

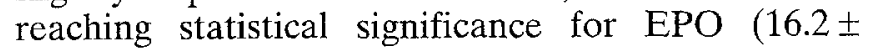
$3.7 \%, \mathrm{p}<0.01)$, ZD5522 $(16.0 \pm 2.8 \%, p<0.05)$ and WAY121509 (20.4 $\pm 3.4 \%, p<0.01)$. Joint ZD5522/ 

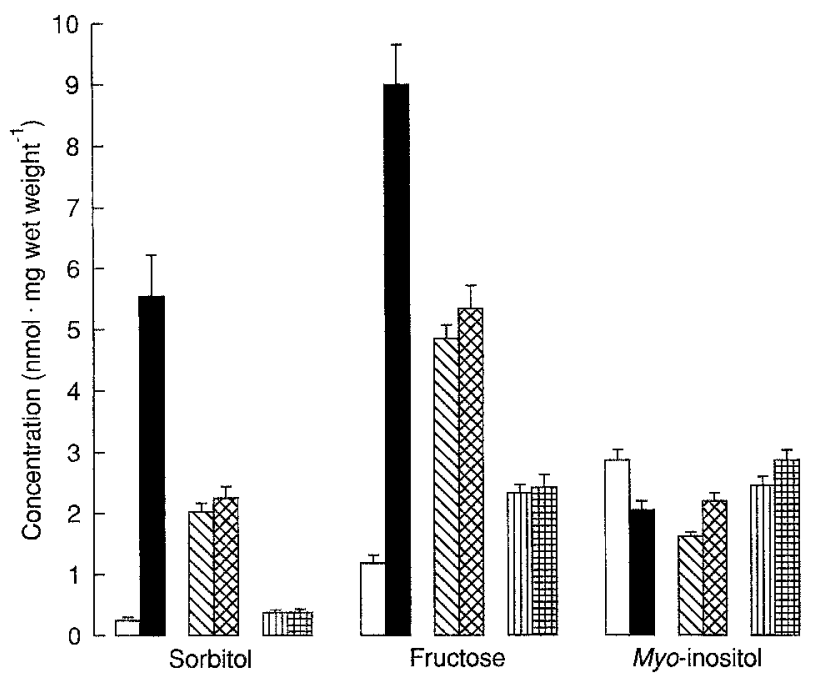

Fig. 1. Sciatic nerve sorbitol, fructose and myo-inositol concentrations from non-diabetic, diabetic and ARI and EPO treated diabetic groups. Non-diabetic group $(\square), n=10$; 8-week diabetic group (,$n=10 ; 8$-week diabetic group treated for the last 2 weeks with $0.25 \mathrm{mg} \cdot \mathrm{kg}^{-1} \cdot \mathrm{day}^{-1} \mathrm{ZD} 5522$ ( $), n=9$; diabetic group treated with ZD5522 + a $0.1 \%$ dietary supplement of EPO ( 2 weeks with $0.2 \mathrm{mg} \cdot \mathrm{kg}^{-1}$. day ${ }^{-1}$ WAY121 $509($ 四), $n=9$; diabetic group treated with WAY 121509 + a $0.1 \%$ dietary supplement of EPO (平), $n=9$. Statistics: sorbitol, non-diabetic vs diabetic $p<0.001$, non-diabetic vs ZD5522-treated diabetic and ZD5522 + EPO treated diabetic $p<0.01$, diabetic vs WAY 121509 treated diabetic and WAY121509 + EPO treated diabetic $p<0.001$, all other comparisons NS. Fructose, non-diabetic vs all other groups $p<0.001$, diabetic vs ZD5522 or WAY121509 treated diabetic without or with EPO treatment $p<0.001$, WAY121509 treated diabetic without or with EPO treatment vs ZD5522 treated diabetic without or with EPO treatment $p<0.001$. Myo-inositol, non-diabetic vs diabetic or ZD5522-treated diabetic $p<0.001$, non-diabetic vs ZD5522 + EPO treated diabetic $p<0.01$, diabetic vs WAY121509+EPO treated diabetic $p<0.01$

EPO treatment produced a $71.5 \pm 7.4 \%$ reversal $(p<0.001)$ that, while remaining diminished compared to the non-diabetic group $(p<0.01)$, nevertheless markedly exceeded the magnitude of effect expected from the sum of the individual NCV elevations (one sample Student's $t$-test, $p=0.0008$ ). The combination of WAY121509 and EPO caused a similar correction of NCV $(82.4 \pm 2.8 \%, p<0.001)$ which was greatly enhanced compared to expectations based on additivity of drug effects (one sample Student's $t$-test, $p<0.0001$ ).

Sciatic nutritive endoneurial blood flow (Fig. 3A) was $43.1 \pm 2.8 \%$ depressed by 8 weeks of diabetes $(p<0.001)$. Treatment for the final 2 weeks with ZD5522 or EPO caused numerical increases that were not statistically significant. For joint treatment, the degree of correction of the flow deficit was $67.8 \pm 13.4 \%(p<0.001)$ which exceeded the sum of individual drug effects (one sample Student's $t$-test, $p=0.015$ ). However, flow remained $13.9 \pm 5.8 \%$ $(p<0.05)$ below the non-diabetic level.

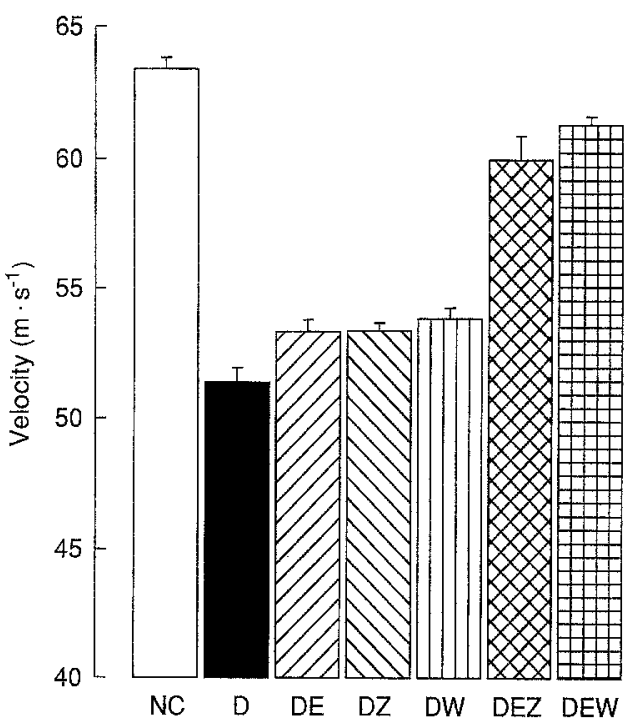

Fig. 2. Effects of diabetes and threshold doses of ARI and $\mathrm{EPO}$, alone and in combination, on sciatic motor NCV. NC, non-diabetic control group, $n=11$; D, 8-week diabetic group, $n=10 ; \mathrm{DE}, 8$-week diabetic group treated with a $0.1 \%$ dietary supplement of EPO for the last 2 weeks, $n=10$; DZ, 8 -week diabetic group treated with $0.25 \mathrm{mg} \cdot \mathrm{kg}^{-1} \cdot$ day $^{-1} \mathrm{ZD} 5522$ for the last 2 weeks, $n=10$; DW, 8 -week diabetic group treated with $0.2 \mathrm{mg} \cdot \mathrm{kg}^{-1}$. day WAY121509 for the last 2weeks, 9; DEZ, 8-week diabetic group given combined ZD5522 and EPO treatment, $n=9$; DEW, 8-week diabetic group given combined WAY121509 and EPO treatment, $n=9$. Statistics: $\mathrm{NC}$ vs $\mathrm{D}, \mathrm{DE}, \mathrm{DZ}, \mathrm{DW}$, or DEZ, $\mathrm{p}<0.001$; NC vs DEW, $\mathrm{p}<0.01 ; \mathrm{D}$ vs DEZ, DEW, $\mathrm{p}<0.001 ; \mathrm{D}$ vs DE, DW, $\mathrm{p}<0.01$; $D$ vs $D Z, p<0.05 ; D Z$ vs DEZ and DW vs DEW and DE vs DEZ and DEW, $\mathrm{p}<0.001$; all other comparisons NS

Blood pressure (Fig. 3B) tended to be reduced by diabetes and treatment, differences being significant for EPO $(p<0.01)$ and joint EPO-ZD5522 $(p<0.05)$ treatments compared to the non-diabetic group. As peripheral nerve vascular supply has minimal autoregulatory responses to changes in blood pressure [1], this would exacerbate the effects of diabetes and minimize treatment effects on vasa nervorum. When blood pressure differences were taken into account by expressing the data as vascular conductance (Fig. 3 C), there was a $37.5 \pm 2.5 \%$ reduction in sciatic nutritive conductance in the untreated diabetic group $(p<0.001)$ compared to non-diabetic controls. Small but statistically significant $(p<0.05) 23.3 \pm 3.9$ and $21.3 \pm 8.3 \%$ corrections were found with EPO and ZD5522 treatments, respectively. For the joint EPOZD5522 treatment group, conductance was within the non-diabetic range, significantly improved compared to the untreated diabetic group $(p<0.001)$ and greater than expected from the sum of individual drug effects (one sample Student's $t$-test, $p=0.046$ ).

Study 2: effects of flurbiprofen and $N^{G}$-nitro-L-arginine treatment on conduction velocity and endoneurial blood flow in untreated diabetic rats and diabetic rats treated with high doses of evening primrose oil or 

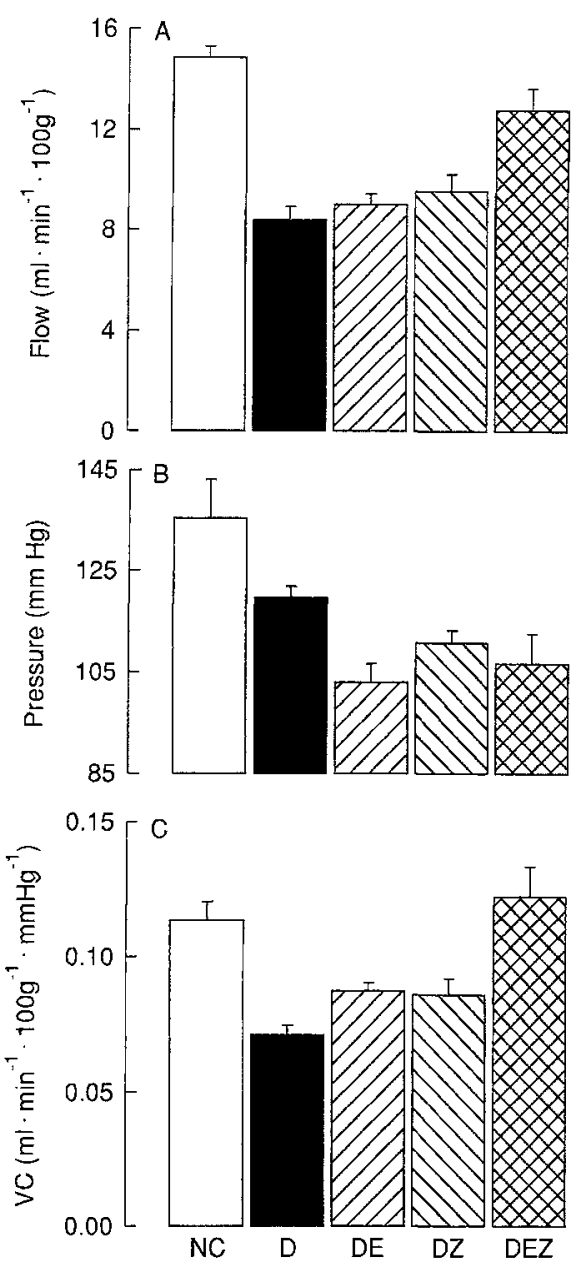

Fig. 3. (A-C) Effects of diabetes and threshold doses of ARI and EPO, alone and in combination, on sciatic nutritive endoneurial blood flow $(\mathbf{A})$, mean systemic blood pressure $(\mathbf{B})$ and endoneurial vascular conductance $(\mathrm{VC})(\mathbf{C})$. NC, non-diabetic control group, $\mathrm{n}=11 ; \mathrm{D}, 8$-week diabetic group, $\mathrm{n}=10$; DE, 8 week diabetic group treated with a $0.1 \%$ dietary supplement of EPO for the last 2 weeks, $\mathrm{n}=10 ; \mathrm{DZ}, 8$-week diabetic group treated with $0.25 \mathrm{mg} \cdot \mathrm{kg}^{-1} \cdot$ day $^{-1}$ ZD5522 for the last 2 weeks, $n=10 ; \mathrm{DEZ}, 8$-week diabetic group given combined ZD5522 and EPO treatment, $n=9$. Statistics: blood flow, NC vs D, $\mathrm{DE}, \mathrm{DZ}, p<0.001$; NC vs DEZ, $p<0.05$; DEZ vs D or DE or $\mathrm{DZ}, p<0.001$. Blood pressure, $\mathrm{NC}$ vs $\mathrm{DE}, p<0.01 ; \mathrm{NC}$ vs DEZ, $p<0.05 ; \mathrm{D}$ vs DE, $p<0.05$. Vascular conductance, $\mathrm{NC}$ vs $\mathrm{D}, p<0.001$; NC vs DE, DZ, $p<0.01$; D vs DEZ, $p<0.001$; $\mathrm{D}$ vs DE, DZ, $p<0.05$; DEZ vs DE, DZ, $p<0.01$

the ARI, WAY121509. Plasma glucose concentrations, body weights and nerve polyol and myo-inositol levels are shown in Table 2. There were no significant differences in the glucose concentrations between the diabetic groups. However, body weights tended to be higher for the EPO treated diabetic rats, including those co-treated with flurbiprofen and NOLA, than for the other diabetic groups $(p<0.05)$. This may partly reflect the higher initial weights of these groups. An effect of EPO on body weight was not observed in previous studies using similar doses $[9,22,23]$. Sciatic nerve sorbitol and fructose levels were elevated by diabetes 12.5 -fold $(p<0.01)$ and
4.9 -fold ( $p<0.001)$, respectively. This was not significantly altered by EPO or NOLA treatments. With WAY 121509 , both sorbitol $(p<0.001)$ and fructose $(p<0.001)$ were reduced compared to untreated diabetes, remaining at or below the non-diabetic level, and were unaffected by co-treatment with flurbiprofen or NOLA. Nerve $m y o$-inositol concentration was $48.9 \pm 2.7 \%$ reduced by untreated diabetes $(p<0.001)$. There was a tendency for the deficit to be partially prevented by WAY 121509 , alone $(p<0.01)$ or in combination with flurbiprofen $(p<0.001)$. Nerve myo-inositol levels were significantly increased in groups of diabetic rats treated with NOLA alone $(p<0.01)$, or NOLA in combination with EPO $(p<0.001)$ or WAY121509 $(p<0.001)$. In the latter group, nerve myo-inositol concentration was also significantly elevated $(p<0.01)$ compared to the non-diabetic control group.

Sciatic motor NCV (Fig. 4) was $20.0 \pm 0.7 \%$ decreased by 1 month of diabetes $(p<0.001)$. This was almost completely prevented by high dose EPO $(95.5 \pm 5.1 \%, p<0.001)$ or WAY121509 (99.1 \pm $7.2 \%, p<0.001)$ treatment from the induction of diabetes. Flurbiprofen and NOLA treatments tended to modestly exacerbate NCV deficits compared to untreated diabetes, although this was not statistically significant. EPO effects were completely prevented by flurbiprofen $(p<0.001)$ and NOLA $(p<0.001)$. The beneficial effect of WAY121509 treatment was also completely prevented by NOLA $(p<0.001)$. While flurbiprofen treatment also markedly attenuated the effects of WAY121509 by $71.0 \pm 11.9 \%$ $(p<0.001), \mathrm{NCV}$ in diabetic rats receiving this dual treatment remained significantly greater than observed in the untreated diabetic group $(p<0.01)$.

Figure $5 \mathrm{~A}$ shows sciatic nutritive endoneurial blood flow, which was $45.7 \pm 3.2 \%$ reduced by 1 month of diabetes. With flurbiprofen or NOLA treatment of diabetic rats, the deficits were $54.4 \pm 3.4 \%$ and $54.9 \pm 3.8 \%$, respectively, which were not significantly different from untreated diabetes. EPO and WAY121509 treatments completely prevented the blood flow deficit $(p<0.001)$. However, as for NCV, flurbiprofen negated the effect of EPO $(p<0.001)$ and markedly attenuated that of WAY121509 $(91.2 \pm 4.0 \%, \quad p<0.001)$. Similarly, NOLA treatment comprehensively prevented ARI and EPO effects $(p<0.001)$. Systemic blood pressure varied between groups (Fig. 5B). Values were significantly higher in the non-diabetic control group than in the untreated diabetic group $(p<0.01)$, or in diabetic rats treated with WAY121509 $(p<0.05)$ or flurbiprofen $(p<0.05)$. Blood pressure tended to be elevated for diabetic rats treated with NOLA, for example when combined with EPO $(p<0.001$ vs the untreated diabetic group). To take into account these perfusion pressure variations, the flow data are ex- 
N.E. Cameron et al:: Fatty acid and polyol neurovascular interactions

Table 2. Plasma glucose, body weights and sciatic nerve sorbitol, fructose and myo-inositol concentrations for the groups in study 2

\begin{tabular}{|c|c|c|c|c|c|c|c|}
\hline \multirow[t]{2}{*}{ Group } & \multirow[t]{2}{*}{$n$} & \multirow{2}{*}{$\begin{array}{l}\text { Plasma glucose } \\
\left(\mathrm{mmol} \cdot \mathrm{I}^{-1}\right)\end{array}$} & \multicolumn{2}{|c|}{ Body weight $(\mathrm{g})$} & \multicolumn{3}{|c|}{ Nerve polyols $\left(\mathrm{nmol} \cdot \mathrm{mg}\right.$ wet weight ${ }^{-1}$ ) } \\
\hline & & & Initial & Final & Sorbitol & Fructose & Myo-inositol \\
\hline Non-diabetic control & 14 & $7.2 \pm 0.5$ & $463 \pm 8$ & - & $0.329 \pm 0.032$ & $1.41 \pm 0.06$ & $3.09 \pm 0.11$ \\
\hline Untreated & 15 & $39.5 \pm 1.6^{\mathrm{a}}$ & $465 \pm 7$ & $353 \pm 11^{\mathrm{a}}$ & $4.109 \pm 0.18^{b}$ & $6.90 \pm 0.34^{\mathrm{a}}$ & $1.58 \pm 0.08^{\mathrm{a}}$ \\
\hline & 10 & $38.3 \pm 1.6^{\mathrm{a}}$ & $454 \pm 14$ & $351 \pm 15^{\mathrm{a}}$ & $3.801 \pm 0.119^{\mathrm{c}}$ & $5.72 \pm 0.21^{\mathrm{a}}$ & $2.15 \pm 0.10^{\text {ae }}$ \\
\hline + flurbiprofen & 12 & $38.2 \pm 0.9^{\mathrm{a}}$ & $457 \pm 7$ & $345 \pm 7^{\mathrm{a}}$ & not determined & & \\
\hline$+\mathrm{EPO}+$ flurbiprofen & 9 & $40.4 \pm 1.7^{\mathrm{a}}$ & $468 \pm 7$ & $392 \pm 9^{\mathrm{a}}$ & $2.140 \pm 0.213$ & $4.56 \pm 0.25^{\mathrm{a}}$ & $2.03 \pm 0.13^{\mathrm{a}}$ \\
\hline + WAY121509 & 12 & $41.9 \pm 2.1^{\mathrm{a}}$ & $441 \pm 7$ & $333 \pm 9^{\mathrm{a}}$ & $0.018 \pm 0.002^{\mathrm{d}}$ & $0.22 \pm 0.02^{\mathrm{ad}}$ & $2.13 \pm 0.13^{\mathrm{ae}}$ \\
\hline + WAY121509 + NOLA & 11 & $39.4 \pm 1.5^{\mathrm{a}}$ & $460 \pm 5$ & $345 \pm 8^{\mathrm{a}}$ & $0.048 \pm 0.005^{\mathrm{d}}$ & $0.27 \pm 0.02^{\mathrm{ad}}$ & $4.46 \pm 0.31^{\text {bdf }}$ \\
\hline + WAY121509 + flurbiprofen & 12 & $39.7 \pm 1.7^{\mathrm{a}}$ & $442 \pm 8$ & $343 \pm 9^{\mathrm{a}}$ & $0.016 \pm 0.001^{d}$ & $0.21 \pm 0.01^{\mathrm{ad}}$ & $2.47 \pm 0.13^{d}$ \\
\hline
\end{tabular}

Data are group means \pm SEM

${ }^{\mathrm{a}} p<0.001 ;{ }^{\mathrm{b}} p<0.01 ;{ }^{\mathrm{c}} p<0.05$ vs non-diabetic control group;

${ }^{\mathrm{d}} p<0.001 ;{ }^{\mathrm{e}} p<0.01$ vs untreated diabetic group;

${ }^{\mathrm{f}} p<0.001 ;{ }^{\mathrm{g}} p<0.01$ effect of co-treatment with NOLA

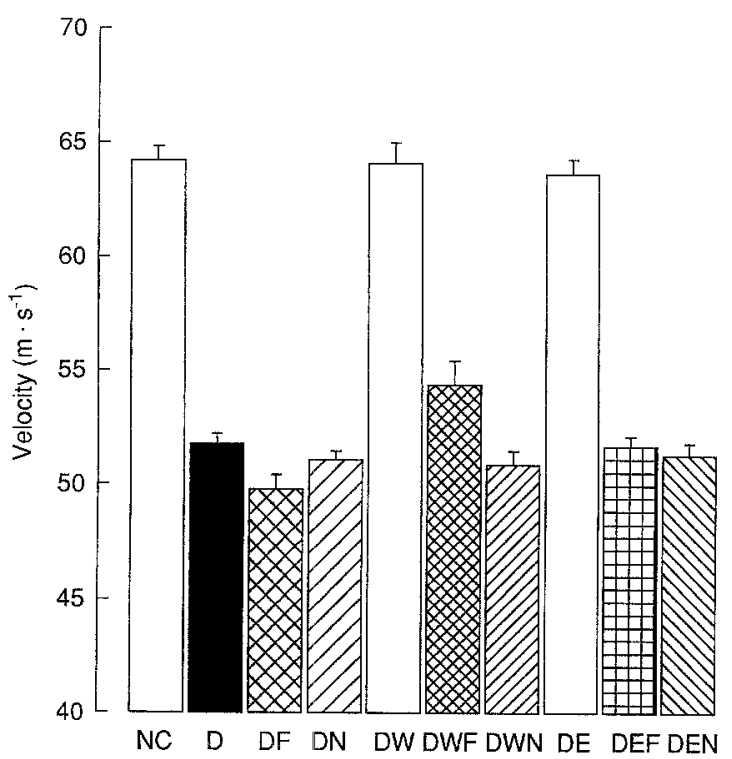

Fig.4. Effects of diabetes and treatment with high doses of an ARI or EPO, alone or in combination with the cyclo-oxygenase inhibitor, flurbiprofen, or the $\mathrm{NO}$ synthase inhibitor, $\mathrm{N}^{\mathrm{G}}$ nitro-L-arginine on sciatic motor NCV. NC, non-diabetic control group, $n=14$; D, 4-week diabetic group, $n=15$; DF, 4week diabetic group treated from induction with $5 \mathrm{mg}$. $\mathrm{kg}^{-1} \cdot$ day $^{-1}$ flurbiprofen, $n=12 ; \mathrm{DN}$, 4-week diabetic group treated from induction with $10 \mathrm{mg} \cdot \mathrm{kg}^{-1} \cdot$ day $^{-1} \mathrm{~N}^{\mathrm{G}}$-nitro-Larginine, $n=10$; $\mathrm{DW}$, 4-week diabetic group treated from induction with $10 \mathrm{mg} \cdot \mathrm{kg}^{-1} \cdot \mathrm{day}^{-1}$ WAY $121509, n=12$; DWF, diabetic group treated with WAY121509 and flurbiprofen, $n=12$; DWN, diabetic group treated with WAY121509 and $\mathrm{N}^{\mathrm{G}}$-nitro-L-arginine, $n=11$; DE, 4-week diabetic group treated from induction with a $10 \%$ dietary supplement of EPO, $n=10$; DEF, diabetic group treated with EPO and flurbiprofen, $n=9$; DEN, diabetic group treated with EPO and $\mathrm{N}^{\mathrm{G}}$-nitro-Larginine, $n=11$. Statistics NC vs D, DF, DN, DWF, DWN, $\mathrm{DEF}, \mathrm{DEN}, p<0.001$; D vs DE, DW, $p<0.001$; D vs DWF, $p<0.01$; DE vs DEF and DEN, and DW vs DWF and DWN, $p<0.001$ pressed as vascular conductance in Figure 5C. Conductance was $37.3 \pm 2.7 \%$ reduced by untreated diabetes $(p<0.001)$. With flurbiprofen the conductance deficit was $48.2 \pm 4.3 \%(p<0.001$ vs the control, NS vs the diabetic group) and with NOLA, $57.7 \pm 3.2 \%$ ( $p<0.001$ vs the control, $p<0.001$ vs the diabetic group). With EPO and WAY121509 treatments, conductances were at the top end of the non-diabetic range, significantly $(p<0.001)$ elevated compared to untreated diabetes. The combined flurbiprofen + WAY121509 treatment group had conductances within the untreated diabetic range, markedly reduced compared to WAY121509 treatment alone $(p<0.001)$. WAY $121509+$ NOLA treatment reduced conductance $(p<0.001)$ to below that of the untreated diabetic group $(p<0.05)$. Similarly, $\mathrm{EPO}+$ flurbiprofen treated diabetic rats had conductances not significantly different from untreated diabetes, and values for the EPO + NOLA group were depressed below the untreated diabetic level $(p<0.001)$.

Hydrogen clearance curves for peripheral nerves are generally composed of two simultaneously recorded components. A fast component arises due to clearance by large vessels (non-nutritive arterial, venous and particularly arteriovenous flow), and a slow component appears as the result of nutritive (capillary) clearance $[1,14,20]$. Data for composite (total endoneurial) flow and conductance are given in Figure $6 \mathrm{~A}$ and $\mathrm{B}$, respectively. Composite flow was $50.7 \pm 4.8 \%$ and conductance was $43.1 \pm 4.7 \%$ reduced $(p<0.01)$ by 1 month of diabetes. Flurbiprofen treatment tended to exacerbate these abnormalities, although not to a statistically significant extent compared to untreated diabetic rats. NOLA treatment caused large reductions in composite flow $(76.8 \pm 1.9 \%$ deficit $)$ and conductance $(78.2 \pm 1.5 \%$ deficit) which were significantly greater than for untreated diabetes alone $(p<0.01)$. For WAY121509 treatment, neither composite flow nor conductance were significantly elevated compared to the un- 

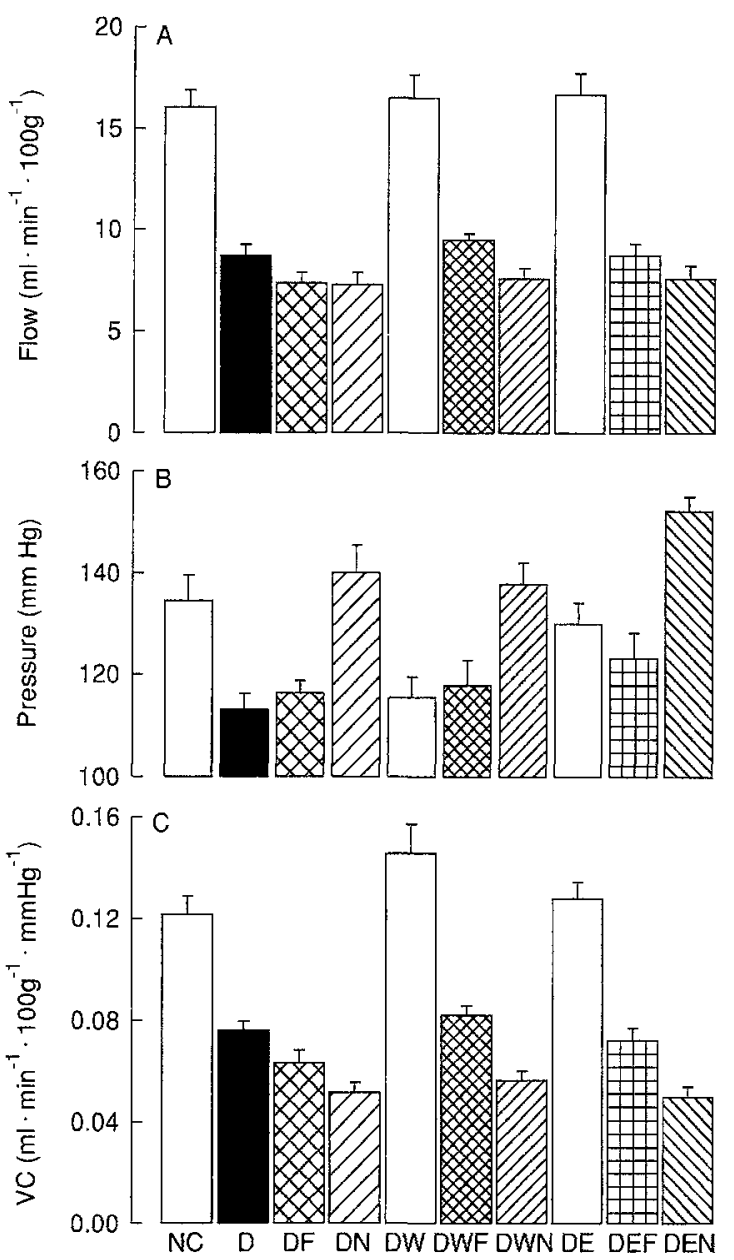

Fig. 5 A-C. Effects of diabetes and treatment with high doses of an ARI or EPO, alone or in combination with the cyclo-oxygenase inhibitor, flurbiprofen, or the nitric oxide synthase inhibitor, NOLA on (A) sciatic nutritive endoneurial blood flow, (B) mean systemic blood pressure and (C) endoneurial vascular conductance (VC). NC, non-diabetic control group, $n=14$; $\mathrm{D}$, 4-week diabetic group, $n=15$; DF, 4-week diabetic group treated from induction with $5 \mathrm{mg} \cdot \mathrm{kg}^{-1} \cdot$ day $^{-1}$ flurbiprofen, $n=12 ; \mathrm{DN}$, 4-week diabetic group treated from induction with $10 \mathrm{mg} \cdot \mathrm{kg}^{-1} \cdot$ day $^{-1}$ NOLA, $n=10$; DW, 4-week diabetic group treated from induction with $10 \mathrm{mg} \cdot \mathrm{kg}^{-1}$. day ${ }^{-1}$ WAY121509, $n=12$; DWF, diabetic group treated with WAY121509 and flurbiprofen, $n=12$; DWN, diabetic group treated with WAY121509 and NOLA, $n=11$; DE, 4-week diabetic group treated from induction with a $10 \%$ dietary supplement of EPO, $n=10$; DEF, diabetic group treated with EPO and flurbiprofen, $n=9 ; \mathrm{DEN}$, diabetic group treated with EPO and NOLA, $n=11$. Statistics: blood flow, NC vs D, DN, DF, DEF, DEN, DWF, DWN, $p<0.001$; D vs DE, DW, $p<0.001 ; \mathrm{DE}$ vs DEF and DEN, and DW vs DWF and DWN, $p<0.001$. Blood pressure, NC vs D, $p<0.01$; NC vs DF, DW, DWF, DEN, $p<0.05$; D vs DN, DEN, $p<0.001$; D vs DWN, $p<0.01$. Vascular conductance, NC vs D, DF, DN, DEF, DEN, DWF, DWN, $p<0.001$; D vs DN, DE, DW, DEN, $p<0.001$; D vs DWN, $p<0.05$; DE vs DEF and DEN, and DW vs DWF and DWN, $p<0.001$; DF vs DWF, $p<0.05$

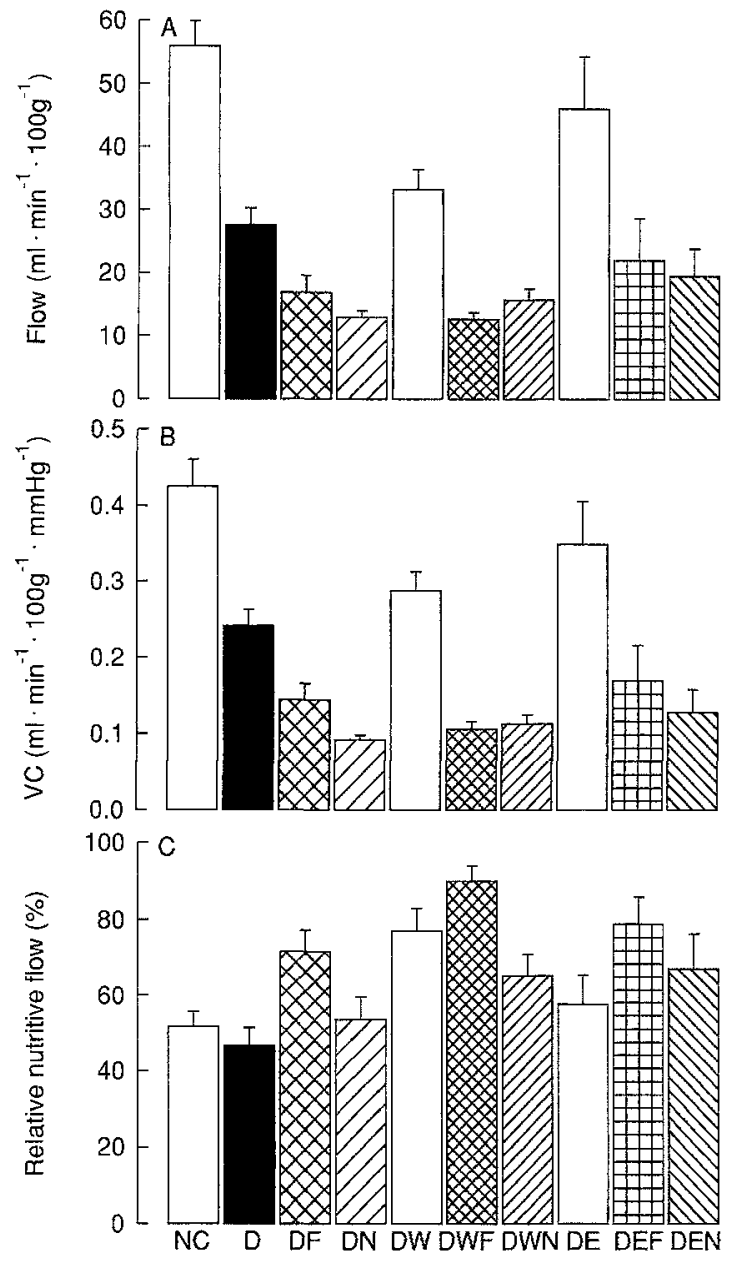

Fig. 6 A-C. Effects of diabetes and treatment with high doses of an ARI or EPO, alone or in combination with the cyclo-oxygenase inhibitor, flurbiprofen, or the nitric oxide synthase inhibitor, NOLA on sciatic (A) composite endoneurial blood flow, (B) composite vascular conductance (VC) and (C) the relative percentage of composite flow that is nutritive. NC, non-diabetic control group, $n=14 ; \mathrm{D}$, 4-week diabetic group, $n=15 ; \mathrm{DF}$, 4-week diabetic group treated from induction with $5 \mathrm{mg}$. $\mathrm{kg}^{-1}$. day ${ }^{-1}$ flurbiprofen, $n=12$; DN, 4-week diabetic group treated from induction with $10 \mathrm{mg} \cdot \mathrm{kg}^{-1} \cdot$ day $^{-1}$ NOLA, $n=10$; DW, 4-week diabetic group treated from induction with 10 $\mathrm{mg} \cdot \mathrm{kg}^{-1} \cdot$ day $^{-1}$ WAY121509, $n=12$; DWF, diabetic group treated with WAY121509 and flurbiprofen, $n=12$; DWN, diabetic group treated with WAY121509 and NOLA, $n=11 ; \mathrm{DE}$, 4-week diabetic group treated from induction with a $10 \%$ dietary supplement of EPO, $n=10$; DEF, diabetic group treated with EPO and flurbiprofen, $n=9 ; \mathrm{DEN}$, diabetic group treated with EPO and NOLA, $n=11$. Statistics: composite blood flow, NC vs D, DF, DN, DW, DWN, DWF, DEN, $p<0.01$; NC vs DEF, $p<0.05$; D vs DN, DWF, $p<0.01$; DW vs DWF, DWN, $p<0.01$. Composite vascular conductance, NC vs D, DF, DN, DWF, DWN, DEN, $p<0.01$; NC vs DEF, $p<0.05 ; \mathrm{D}$ vs DN, DWF, DWN, $p<0.01$; DW vs DWF, DWN, $p<0.01$. Percentage nutritive flow, NC vs DWF, $p<0.001$; NC vs DW, DEF, $p<0.05$; D vs DWF, $p<0.001$; D vs DW, $p<0.01$; D vs DEF, $p<0.05$ 
treated diabetic group, the deficits being $40.5 \pm 5.7 \%$ $(p<0.01)$ and $32.4 \pm 6.1 \%$ (NS) respectively compared to the non-diabetic group. In EPO treated diabetic rats, composite flow and conductance values were intermediate between those of the non-diabetic and untreated diabetic groups and did not differ significantly from them. Flurbiprofen and NOLA cotreatment of WAY121509-treated diabetic rats reduced composite flow and conductance compared to WAY121509 treatment alone $(p<0.01)$ the values being below the untreated diabetic level $(p<0.05)$. For EPO treated rats, flurbiprofen and NOLA resulted in composite flow and conductance deficits not significantly different from those of the untreated diabetic group.

The percentage of hydrogen clearance via nutritive perfusion (Fig. 6C), an index of the pattern of endoneurial blood flow and degree of arteriovenous shunting $[14,20,24]$, varied between groups. It was not significantly affected by diabetes, EPO or NOLA treatments. However, the percentage of nutritive flow was elevated by $65.5 \pm 12.6 \%$ with WAY121509 $(p<0.01)$ and flurbiprofen treatments (without EPO $53.9 \pm 11.8 \%$ or with EPO $69.1 \pm$ $15.1 \%, p<0.05)$ compared to untreated diabetes. The largest elevation $(93.1 \pm 8.2 \%, p<0.001)$ was noted for combined WAY121509+flurbiprofen treatment. In this group, the non-nutritive component was only detected in 5 out of 12 rats.

Taking the data from studies 1 and 2 together for treated diabetic rats, there was a strong positive correlation between nutritive blood flow, as the independent variable, and conduction velocity as the dependent variable $(r=0.79, p<0.0001)$.

\section{Discussion}

Data from the first study reveal a marked facilitation between low level essential fatty acid treatment and polyol pathway blockade in diabetic rats. Thus, doseresponse curve estimates for correction of NCV deficits by EPO and ZD5522 [14, 17] show that adding the EPO to ZD5522 gave an effect equivalent to a 13.3-fold increase in the dose of ZD5522. Similarly, addition of ZD5522 to the EPO would be matched by a 6.8 -fold increase in the dose of EPO. These figures compare with 1.8-fold and 0.8-fold dose increases predicted for simple additivity of NCV effects for ZD5522 and EPO, respectively. Although comprehensive dose-response data are not available for WAY121509 in this diabetic model, the "threshold" dose was extrapolated from NCV effects for higher doses [18]. The results show a similar interaction with EPO, thus generalizing the effect to a structurally dissimilar ARI. NCV corrections by the two ARIs were similar; however, at the chosen doses WAY121509 produced a greater blockade of nerve polyol accumulation than ZD5522. The magnitude of ARI-mediated NCV effects and their partial dissociation from the degree of polyol pathway inhibition, assessed by nerve metabolite accumulation, is in line with previous research showing that (i) a very high level of blockade is required to remedy neurovascular deficits and (ii) nerve polyol levels are poor predictors of functional effects $[14,18,25]$. Sciatic NCV changes with ZD5522, EPO and joint treatment paralleled changes in nutritive blood flow and vascular conductance; therefore, the most functionally relevant site for polyol measurements would be vasa nervorum vessels rather than the nerve itself. EPO co-treatment did not alter the effectiveness of ZD5522 and WAY121509 against nerve polyol accumulation, which argues for different mechanisms of action for essential fatty acids and ARIs in a multifactorial pathogenesis [2].

EPO probably acts to supply $\gamma$-linolenic acid for prostanoid synthesis, bypassing a diabetes-induced defect in hepatic $\Delta-6$ desaturation of linoleic acid [2]. This would increase vasa nervorum prostacyclin production, accounting for the elevation of nutritive blood flow in the second study $[8,9,17]$. For ARIs, a major effect is the correction of an NO-mediated endothelium-dependent relaxation deficit due to restoration of NADPH, a consequence of the reduced NADPH-dependent conversion of glucose to sorbitol $[7,26-28]$. This could act in at least two ways; NO synthase requires NADPH as co-substrate and, probably more important, NADPH is necessary for glutathione reduction by glutathione reductase. The reduced form of glutathione is part of the endogenous scavenging mechanism limiting oxygen free radical activity, which would otherwise react with NO and prevent vasodilation [12]. Thus, the vascular effects of EPO and ARI treatments can be identified with increased prostacyclin and NO action respectively, although this may be an oversimplification since ARI treatment partially corrected reduced aorta prostacyclin output [29] and a deficit in the pressor response to arachidonic acid [30] in diabetic rats. No effects of EPO on polyol pathway metabolites were observed, in agreement with previous findings [31, 32].

The second study showed that high doses of WAY121509 and EPO prevented NCV and nutritive blood flow deficits in diabetic rats. In contrast, neither agent alters nutritive perfusion in non-diabetic rats $[9,18]$. NOLA further decreased nerve vascular conductance in diabetic rats, although an effect on nutritive flow was minimized by increased blood pressure due to generalized vasoconstriction. NOLA abolished the ARI effect on nutritive flow, conductance and NCV, as expected if ARIs act to improve the NO system. However, NOLA also prevented EPO's action. NOLA is a specific NO synthase inhibitor and was used at a moderate dose that would not be expected to affect prostanoid synthesis $[16$, 
33]. In vasa nervorum of diabetic rats, prostacyclin synthetic enzymes are upregulated and the prostacyclin deficit is primarily caused by reduced substrate availability [6]. Inhibition of the action of EPO by NOLA could be explained by the synergistic mechanism suggested by the first study. Thus, if the vasodilation caused by EPO-mediated prostacylin synthesis in diabetes was facilitated by the remaining basal NO output from vasa nervorum endothelium, then withdrawal of this NO support would effectively reduce EPO action. Vasa nervorum conductance was below the diabetic level in EPO + NOLA-treated rats. The converse argument may explain the effects of flurbiprofen, an agent with high specificity used at a moderate dose $[34,35]$, in blocking ARI action. Thus, ARI-mediated NO improvements are underpinned by prostacyclin support, the joint neurovascular effect collapsing with flurbiprofen treatment. In the longer term, flurbiprofen and NOLA cause endoneurial capillary regression $[16,22]$ presumably reflecting the chronic decrease in vascular conductance.

Recently it was shown that the effects of sorbinil on NCV are prevented by the NO synthase inhibitor, $\mathrm{N}^{G}$-nitro-L-arginine methyl ester [36]; evidence that was taken to support the hypothesis that NADPH competition between aldose reductase and NO synthase is responsible for reduced vascular NO production [7]. The findings of the second study agree with this evidence; however, they also show that such a conclusion is an overinterpretation because it does not take into account interactions between polyol and essential fatty acid mechanisms. While the effects of sorbinil on NCV were blocked by $\mathrm{N}^{\mathrm{G}}$-nitro-L-arginine methyl ester, those for dietary myo-inositol supplementation were not [36]. This indicates that ARIs do not work via myo-inositol changes [14], however, the mechanism of myo-inositol's action is unclear. Myo-inositol does not affect endoneurial blood flow or NCV in our diabetic model $[14,37]$ and it did not alter the increased systemic blood pressure caused by $\mathrm{N}^{\mathrm{G}}$-nitro-L-arginine methyl ester [36] indicating a lack of vascular action. It was suggested that prevention of NCV changes by myo-inositol were mediated by increased Na-K ATPase activity [36] as previously hypothesized for ARIs [38]. However, it is questionable whether an elevated Na-K ATPase activity could be supplied with sufficient ATP in vivo, given the existing endoneurial hypoxia of diabetes $[1,14]$ further exacerbated by decreased vasa nervorum conductance consequent on NO synthase inhibition. In addition, nerve myo-inositol levels were markedly elevated by NOLA in conjunction with WAY121509 and EPO treatments, although these groups had NCVs in the diabetic range. Myo-inositol levels were also normal for joint sorbinil - $\mathrm{N}^{\mathrm{G}}$-nitro-L-arginine methyl ester treatment in the presence of a NCV deficit [36]. Taken together, these data suggest that a myo-inositol/Na-K ATPase mechanism is unlikely to contribute to the NCV or blood flow results. Furthermore, NCV deficits are corrected by vasodilator or EPO treatments that do not alter Na-K ATPase activity [32, 39] and ARI/myo-inositol effects on Na-K ATPase are only found in rats fed a high sucrose diet [40].

This study shows that whenever nutritive blood flow is reduced so is NCV. Thus, when polyol pathway hyperactivity is corrected by ARI treatment, NCV effects are negated if the vascular benefits are blocked by NOLA or flurbiprofen. Nerve polyols nevertheless remain in the non-diabetic range, thus, a putative "pseudohypoxia" mechanism, based on changes in neuronal NADH/NAD ratio due to flux through the second half of the polyol pathway [41] is unlikely to cause the NCV reduction. Conversely, blood flow and NCV are restored by EPO and vasodilator treatments $[2,4,5,19,39]$ although polyol pathway and pseudohypoxia mechanisms remain strongly activated. Thus, it must be concluded that pseudohypoxia does not contribute significantly to diabetic NCV changes and that neurovascular mechanisms predominate.

Treatment-induced changes in non-nutritive perfusion and blood flow patterns were evident in the second study. Thus, WAY121 509 had little effect on the composite flow deficit in diabetic rats but the percentage of nutritive clearance was increased. This agrees with previous high-dose ARI studies [14, 18] and may indicate diversion of arterio-venous shunt flow to the capillary bed. In contrast, EPO treatment caused a generalized flow increase; both composite and nutritive perfusion were elevated and the percentage of nutritive clearance remained unaltered [9]. NOLA treatment tended to suppress flow without altering the flow pattern, reducing the effects of both WAY121509 and EPO. Flurbiprofen also markedly reduced composite flow, while at the same time increasing the percentage flow going through the capillary bed. Although the latter did not actually improve nutritive flow, it may have offset a further potential reduction. Interestingly the group with the highest percentage of nutritive flow was treated with the WAY121509-flurbiprofen combination, the value being consistent with additivity for arterio-venous shunt closure. Reasons for these effects are unclear; arterio-venous shunts are closed by serotonin [20] and ARI treatment improved the aortic contractile responses to serotonin in diabetic rats [7] which may, therefore, apply to vasa nervorum. Prostacyclin can antagonise the action serotonin [42], which might explain the effects of flurbiprofen.

Interactions between $\mathrm{NO}$ and prostacyclin mechanisms exist at the receptor/transduction level [42], therefore, synergism is not restricted to diabetes. Non-diabetic rats treated jointly with flurbiprofen and NOLA revealed a fivefold amplification effect for reduced NCV [16]. Other interactions could po- 
tentially be important in vasa nervorum, for example, facilitation of noradrenergic activation by angiotensin II [43]. The diabetic neurovascular deficit appears to result from a complex of changes in several interacting control systems including those responsible for synthesis of NO, prostanoids, angiotensin II, endothelin 1, and for sympathetic tone [2]. Normally, a degree of mutual compensatory action in these overlapping systems maintains vasa nervorum in a state capable of delivering ample perfusion, and confers a relative resistance to dysfunction of a single mechanism [16]. However, with the multiple deficits in diabetes this compensatory ability is lost, resulting in nerve dysfunction. Such a view could partly explain why several therapeutic approaches give nearly complete protection against reduced NCV in diabetic rats. Thus, correction of a single important mechanism such as NO action $[14,15]$ or elevated angiotensin II vasoconstriction [4] would allow normal blood flow despite partial defects remaining in other control mechanisms.

In conclusion, the data show a synergistic interaction between cyclo-oxygenase and NO synthase mediated neurovascular actions that can markedly amplify responses to joint ARI and EPO treatment. If the same mechanism operates in human diabetic patients, the positive aspect of this interaction could potentially be harnessed to provide a therapeutic advantage in diabetic neuropathy.

Acknowledgements. N.E.C. was supported by a Wellcome Trust Research Leave Fellowship. We thank Scotia Pharmaceuticals and Zeneca Pharmaceuticals for the gifts of evening primrose oil and ZD5522.

\section{References}

1. Low PA, Lagerlund TD, McManis PG (1989) Nerve blood flow and oxygen delivery in normal, diabetic and ischemic neuropathy. Int Rev Neurobiol 31: $355-438$

2. Cameron NE, Cotter MA (1994) The relationship of vascular changes to metabolic factors in diabetes mellitus and their role in the development of peripheral nerve complications. Diabetes Metab Rev 10: 189-224

3. Tesfaye S, Malik R, Ward JD (1994) Vascular factors in diabetic neuropathy. Diabetologia 37: 847-854

4. Maxfield EK, Cameron NE, Cotter MA, Dines KC (1993) Angiotensin II receptor blockade improves nerve function, modulates nerve blood flow and stimulates endoneurial angiogenesis in streptozotocin-diabetic rats. Diabetologia 36: 1230-1237

5. Cameron NE, Dines KC, Cotter MA (1994) The potential contribution of endothelin-1 to neurovascular abnormalities in streptozotocin-diabetic rats. Diabetologia 37: 12091215

6. Ward KK, Low PA, Schmelzer JD, Zochodne DW (1989) Prostacyclin and noradrenaline in peripheral nerve of chronic experimental diabetes in rats. Brain 112: 197-208

7. Cameron NE, Cotter MA (1992) Impaired contraction and relaxation in aorta from streptozotocin-diabetic rats: role of polyol pathway. Diabetologia 35: 1011-1019
8. Stevens EJ, Carrington AL, Tomlinson DR (1993) Prostacyclin release in experimental diabetes: effects of evening primrose oil. Prostaglandins Leukot Essent Fatty Acids 49: 699-706

9. Cameron NE, Cotter MA (1994) Effects of evening primrose oil treatment on sciatic nerve blood flow and endoneurial oxygen tension in streptozotocin-diabetic rats. Acta Diabetol 31: 220-225

10. Dines KC, Cotter MA, Cameron NE (1993) Contrasting effects of treatment with $\omega-3$ and $\omega-6$ essential fatty acids on peripheral nerve function and capillarization in streptozotocin-diabetic rats. Diabetologia 36: 1132-1138

11. Julu POO (1988) Essential fatty acids prevent slowed nerve conduction velocity in streptozotocin diabetic rats. J Diabetes Complications 2: 185-188

12. Langenstroer P, Pieper GM (1992) Regulation of spontaneous EDRF release in diabetic rat aorta by oxygen free radicals. Am J Physiol 263:H257-H265

13. Calcutt NA, Mizisin AP, Kalichman MW (1994) Aldose reductase inhibition, Doppler flux and conduction in diabetic rat nerve. Eur J Pharmacol 251: 27-33

14. Cameron NE, Cotter MA, Dines KC, Maxfield EK, Carey F, Mirrlees DJ (1994) Aldose reductase inhibition, nerve perfusion, oxygenation and function in streptozotocin-diabetic rats: dose-response considerations and independence from a myo-inositol mechanism. Diabetologia 37: 651-663

15. Cameron NE, Cotter MA, Archibald V, Dines KC, Maxfield EK (1994) Anti-oxidant and pro-oxidant effects on nerve conduction velocity, endoneurial blood flow and oxygen tension in non-diabetic and streptozotocin-diabetic rats. Diabetologia 37: 449-459

16. Cameron NE, Cotter MA, Dines KC, Maxfield EK (1993) Pharmacological manipulation of vascular endothelium in non-diabetic and streptozotocin-diabetic rats: effects on nerve conduction, hypoxic resistance and endoneurial capillarization. Diabetologia 36: 516-522

17. Dines KC, Cotter MA, Cameron NE (1995) Comparison of the effects of evening primrose oil and triglycerides containing gamma-linolenic acid on nerve conduction and blood flow in diabetic rats. J Pharmacol Exp Ther 273: 49-55

18. Cameron NE, Cotter MA, Dines KC, Hohman TC (1996) Reversal of defective peripheral nerve conduction velocity, nutritive endoneurial blood flow and oxygenation by a novel aldose reductase inhibitor, WAY-121,509, in streptozotocin-diabetic rats. J Diabetes Complications 10:(in press)

19. Cameron NE, Cotter MA, Low PA (1991) Nerve blood flow in early experimental diabetes in rats: relation to conduction deficits. Am J Physiol 261:E1-E8

20. Day TJ, Lagerlund TD, Low PA (1989) Analysis of $\mathrm{H}_{2}$ clearance curves used to measure blood flow in rat sciatic nerve. J Physiol 414: 35-54

21. Zochodne DW, Ho LT (1991) Unique microvascular characteristics of the dorsal root ganglion in the rat. Brain Res 559: 89-93

22. Cameron NE, Cotter MA, Dines KC, Robertson S, Cox D (1993) The effects of evening primrose oil on peripheral nerve function and capillarization in streptozotocin-diabetic rats: modulation by the cyclo-oxygenase inhibitor flurbiprofen. Br J Pharmacol 109: 972-979

23. Cameron NE, Cotter MA, Robertson S (1991) Effects of essential fatty acid dietary supplementation on peripheral nerve and skeletal muscle function and capillarization in streptozocin diabetic rats. Diabetes 40: 532-539

24. Kihara M, Zollman PJ, Smithson IL, Lagerlund TD, Low PA (1994) Hypoxic effect of exogenous insulin on normal and diabetic peripheral nerve. Am J Physiol 266:E980E985 
25. Cameron NE, Cotter MA (1992) Dissociation between biochemical and functional effects of the aldose reductase inhibitor ponalrestat on peripheral nerve in diabetic rats. $\mathrm{Br}$ J Pharmacol 107: 939-944

26. Cohen RA (1993) Dysfunction of vascular endothelium in diabetes mellitus. Circulation 87 [Suppl V]:V67-V76

27. Cameron NE, Cotter MA (1993) Contraction and relaxation of aortas from galactosaemic rats and the effects of aldose reductase inhibition. Eur J Pharmacol 243: 4753

28. Otter DJ, Chess-Williams R (1994) The effects of aldose reductase inhibition with ponalrestat on changes in vascular function in streptozotocin diabetic rats $\mathrm{Br} \mathrm{J}$ Pharmacol 113: $576-580$

29. Wakasugi $M$, Noguchi $T$, Inoue $M$, Tawata $M$, Shindo $H$, Onaya T (1991) Effects of aldose reductase inhibitors on prostacyclin $\left(\mathrm{PGI}_{2}\right)$ synthesis by aortic rings from rats with streptozotocin-induced diabetes. Prostaglandins Leukot Essent Fatty Acids 44: 233-236

30. Law SC, King RG (1990) Effects of ponalrestat on depressor responses to arachidonic acid in streptozotocin-diabetic rats. Gen Pharmacol 21: 135-139

31. Tomlinson DR, Robinson JP, Compton AM, Keen P (1989) Essential fatty acid treatment - effects on nerve conduction, polyol pathway and axonal transport in streptozotocin diabetic rats. Diabetologia 32: 655-659

32. Lockett MJ, Tomlinson DR (1992) The effects of dietary treatment with essential fatty acids on sciatic nerve conduction and activity of the $\mathrm{Na}^{+} / \mathrm{K}^{+}$pump in streptozotocindiabetic rats. Br J Pharmacol 105: 355-360

33. Moore PK, al-Swayeh OA, Chong NWS, Evans RA, Gibson $A(1990) \mathrm{L}^{-} \mathrm{N}^{\mathrm{G}}$-nitro arginine (L-NOARG), a novel, Larginine-reversible inhibitor of endothelium-dependent vasodilation in vitro. Br J Pharmacol 99: 408-412

34. Brogden RN, Heel RC, Speight TM, Avery GS (1979) Flurbiprofen: a review of its pharmacological properties and therapeutic use in rheumatic diseases. Drugs 18: 417-438
35. Meade EA, Smith WL, DeWitt DL (1993) Differential inhibition of prostaglandin endoperoxidase synthase (cyclooxygenase) isozymes by aspirin and other non-steroidal anti-inflamatory drugs. J Biol Chem 268: 6610-6614

36. Stevens MJ, Dananberg J, Feldman EL et al. (1994) The linked roles of nitric oxide, aldose reductase and $\left(\mathrm{Na}^{+}\right.$, $\mathrm{K}^{+}$)-ATPase in the slowing of nerve conduction in the streptozotocin diabetic rat. J Clin Invest 94: 853-859

37. Cameron NE, Cotter MA, Robertson S (1989) The effect of aldose reductase inhibition on the pattern of nerve conduction deficits in diabetic rats. Q J Exp Physiol 74: 917926

38. Greene DA, Lattimer SA, Sima AAF (1988) Pathogenesis and prevention of diabetic neuropathy. Diabetes Metab Rev 4: 201--221

39. Cameron NE, Cotter MA, Ferguson K, Robertson S, Radcliffe MA (1991) Effects of chronic $\alpha$-adrenergic receptor blockade on peripheral nerve conduction, hypoxic resistance, polyols, $\mathrm{Na}^{+}-\mathrm{K}^{+}$-ATPase activity and vascular supply in STZ-D rats. Diabetes 40: 1652-1658

40. Sredy J, Flam BR, Sawicki DR (1991) Adenosine triphosphatase activity in sciatic nerve tissue of streptozocin-induced diabetic rats with and without high dietary sucrose: effects of aldose reductase inhibitors. Proc Soc Exp Biol Med 197: 135-142

41. Williamson JR, Chang K, Frangos M et al. (1993) Hyperglycemic pseudohypoxia and diabetic complications. Diabetes 42: $801-813$

42. Botting R, Vane JR (1989) Mediators and anti-thrombotic properties of the vascular endothelium. Annals Med 21: 31-38

43. Szabo B, Hedler L, Schurr C, Starke K (1990) Peripheral presynaptic facilitatory effect of angiotensin II on noradrenaline release in anesthetized rabbits. J Cardiovasc Pharmacol 15: 968-975 